\title{
Article \\ Study on the Synergistic Extraction of Lithium from Spent Lithium Cobalt Oxide Batteries by Molten Salt Electrolysis and Two-Step Precipitation Method
}

\author{
Hui Li, Haotian Li, Jinglong Liang *, Hongyan Yan and Zongying Cai
}

check for updates

Citation: Li, H.; Li, H.; Liang, J.; Yan, H.; Cai, Z. Study on the Synergistic Extraction of Lithium from Spent Lithium Cobalt Oxide Batteries by Molten Salt Electrolysis and Two-Step Precipitation Method. Crystals 2021, 11, 1163. https://doi.org/10.3390/ cryst11101163

Academic Editors: Jie Dang, Jichao Li, Xuewei Lv, Shuang Yuan and Katarzyna Leszczyńska-Sejda

Received: 22 August 2021

Accepted: 21 September 2021

Published: 24 September 2021

Publisher's Note: MDPI stays neutral with regard to jurisdictional claims in published maps and institutional affiliations.

Copyright: (c) 2021 by the authors. Licensee MDPI, Basel, Switzerland. This article is an open access article distributed under the terms and conditions of the Creative Commons Attribution (CC BY) license (https:// creativecommons.org/licenses/by/ $4.0 /)$.
College of Metallurgy and Energy, North China University of Science and Technology, Tangshan 063210, China; lh@ncst.edu.cn (H.L.); 1i986496033@163.com (H.L.); yanhy@ncst.edu.cn (H.Y.); caizy@ncst.edu.cn (Z.C.)

* Correspondence: lj1@ncst.edu.cn

Abstract: With the continuous development of society, the number of spent lithium-ion batteries has also increased, and the recovery of valuable metals such as $\mathrm{Ni}, \mathrm{Co}$, and $\mathrm{Li}$ has become the main research direction of many scholars. In this paper, the extraction process of lithium that enters the molten salt after $\mathrm{LiCoO}_{2}$ electrolysis is studied. Oxalic acid and phosphate are added to molten salt containing lithium ions to realize the two-part precipitation method to extract lithium. The influence of $\mathrm{pH}$ value, temperature, reaction time, and oxalic acid (or phosphate) addition on the process of oxalic acid calcium removal and phosphate lithium precipitation is analyzed. The results show that the calcium removal rate of oxalic acid has reached $99.72 \%$ (Initial conditions: $\mathrm{PH}=7.0, T=70{ }^{\circ} \mathrm{C}$, $\left.t=1.5 \mathrm{~h}, n\left(\mathrm{H}_{2} \mathrm{C}_{2} \mathrm{O}_{4}\right): n\left(\mathrm{Ca}^{2+}\right)=1.2: 1\right)$. The precipitation of $\mathrm{Li}_{3} \mathrm{PO}_{4}$ obtained in the phosphate extraction experiment of lithium is as high as $88.44 \%$ (Initial conditions: $\mathrm{PH}=8.0, T=70{ }^{\circ} \mathrm{C}, t=1.5 \mathrm{~h}, n$ (actual dosage of $\mathrm{Na}_{3} \mathrm{PO}_{4}$ ): $n$ (theoretical dosage of $\left.\mathrm{Na}_{3} \mathrm{PO}_{4}\right)=1.2: 1$ ). The obtained lithium phosphate crystals show regular spherical particles, which can be seen by SEM.

Keywords: lithium cobalt oxide battery; molten salt electrolysis; oxalate removal of calcium; phosphoric acid to de-deposit lithium

\section{Introduction}

Due to its excellent properties including its high energy density, long cycle life, low self-discharge, and lack of memory effect, lithium-ion batteries are widely used in portable electronic products, hybrid electric vehicles, and large-scale energy storage [1-3]. With the increase in the application of lithium batteries, it is estimated that the output value of lithium batteries will be close to 139.36 billion U.S. dollars by 2026 [4]. There are many types of lithium-ion batteries, such as lithium cobalt oxide batteries [5], lithium iron phosphate batteries [6], ternary material lithium batteries [7], etc. Lithium-ion batteries contain more metal elements such as $\mathrm{Co}, \mathrm{Ni}, \mathrm{Mn}, \mathrm{Li}, \mathrm{Fe}$, and the most widely used lithium cobalt oxide batteries contain up to $20 \%$ and $3 \%$ of $\mathrm{Co}$ and Li. However, the cobalt and lithium content in most cobalt-containing ores in nature is only $0.01 \sim 0.20 \%$. The cost of cobalt smelting is high, and in our country cobalt resources are poor, so the cobalt materials needed for industrial production need to be imported in large quantities [8].

There have always been many problems and difficulties related to the recycling of spent lithium batteries. At this stage, the recycling of resources in spent lithium batteries is not perfect, causing waste of resources and polluting the environment. Compared with natural resources, the grade of lithium in spent lithium batteries is higher than brine and ore, which has a high recovery value [9]. Therefore, while recovering Co, Ni and other metals, the recovery of Li cannot be ignored. The use of molten salt electrolysis to recover valuable metals in the cathode materials of spent lithium batteries can not only recover metals such as $\mathrm{Co}$ and $\mathrm{Ni}$, but $\mathrm{Li}$ in the cathode materials also enters the molten salt. After many electrolysis experiments, Lithium is enriched in molten salt and then extracted by a 
wet method. The method of molten salt electrolysis combined with wet process recovery can realize one-step recovery of $\mathrm{Co}, \mathrm{Ni}$, and other metals, while simultaneously achieving the enrichment of $\mathrm{Li}[10,11]$. This paper mainly studies the problem of lithium extraction in the process of preparing metallic cobalt by electrolysis of $\mathrm{LiCoO}_{2}$ in molten salt. During the electrolysis process, cobalt is attached to the electrode rod in the form of metal, and lithium enters the molten salt. We employ a two-step precipitation method to recover lithium ions in molten salt. First, oxalic acid is added to the molten salt powder containing lithium ions to remove calcium, and phosphate is added to the obtained upper lithium-containing filtrate. Finally a lithium phosphate precipitate is obtained. We then analyze the factors affecting lithium extraction and optimize the process conditions for lithium extraction.

\section{Materials and Methods}

\subsection{Two-Electrode Electrolysis Is Used to Achieve the Extraction of Cobalt in $\mathrm{LiCoO}_{2}$}

Polished and smooth high-purity graphite sheet $(99.99 \%, 20 \mathrm{~mm} \times 5 \mathrm{~mm} \times 100 \mathrm{~mm})$ is used as the anode. $1.0 \mathrm{~g}$ of $\mathrm{LiCoO}_{2}$ powders were pressed into a sheet with a diameter of about $15 \mathrm{~mm}$ and a thickness of about $2 \mathrm{~mm}$, which was sintered at $700{ }^{\circ} \mathrm{C}$ to prepare a cathode. The whole process is carried out in an argon atmosphere. $n(\mathrm{NaCl}): n\left(\mathrm{CaCl}_{2}\right)=1: 1$ is weighed $150 \mathrm{~g}$ and put it into a corundum crucible. The crucible containing the molten salt is placed in the tubular resistance furnace and heated to $750{ }^{\circ} \mathrm{C}$ under the protection of high-purity argon. Then put the two electrodes into the furnace and apply a certain voltage. The cathode is electrolyzed at a constant cell voltage of $1.3 \mathrm{~V}, 12 \mathrm{~h}$ and then taken out, cleaned and dried with ultrasonic waves. Finally, the corresponding phase detection of the cathode product and molten salt is carried out.

\subsection{Calcium Removal Experiment by Oxalic Acid Precipitation Method}

The raw material used in the experiment is molten salt, which is deoxidized by the abovementioned $1.3 \mathrm{~V}, 12 \mathrm{~h}$ electrolytic lithium battery cathode material. In order to ensure that the subsequent lithium ion precipitation effect is obvious and reduce the experimental error, the molten salt after six electrolysis experiments is used as the sample to be tested. Blocked molten salt after cooling is placed in a planetary ball mill and ground at a speed of $170 \mathrm{r} \cdot \mathrm{min}^{-1}$ for $10 \mathrm{~h}$, then the ground powders are placed in a vacuum drying oven and dry at $250^{\circ} \mathrm{C}$ for $48 \mathrm{~h} .5 \mathrm{~g}$ of the dried molten salt powder is weighed, dissolved in $50 \mathrm{~mL}$ of deionized water, and then left to stand for a certain period. Then, the supernatant is taken to different beakers. The beakers are placed in a constant temperature water bath at different temperatures $\left(50^{\circ} \mathrm{C}\right.$, $60{ }^{\circ} \mathrm{C}, 70{ }^{\circ} \mathrm{C}, 80^{\circ} \mathrm{C}, 90^{\circ} \mathrm{C}$ ) and stir for $200 \mathrm{r} \cdot \mathrm{min}^{-1}$. Then, the oxalic acid is added to the corresponding beaker with $n\left(\mathrm{H}_{2} \mathrm{C}_{2} \mathrm{O}_{4}\right): n\left(\mathrm{Ca}^{2+}\right)=(1.0: 1,1.1: 1,1.2: 1,1.3: 1,1.4: 1)$. After reacting for a certain period of time $(0.5 \sim 2.5 \mathrm{~h})$, filter, the content of $\mathrm{Ca}^{2+}$ in the filtrate and the amount of calcium oxalate solid precipitation is determined. The content of residual calcium ions in the solution is determined by titration. First, the $\mathrm{pH}$ of the solution to be tested is adjusted to no less than 12, and the masking agent triethanolamine is added to mask the metal ions such as $\mathrm{Li}^{+}$and $\mathrm{Fe}^{3+}$. Then, calcium red indicator is added until the solution becomes wine red, and then EDTA disodium solution is added until the solution changes from wine red to bright blue. Finally, the EDTA disodium titration is recorded $[12,13]$. The calcium ion content is calculated according to the following Formula (1).

$$
C\left(C a^{2+}\right)=M \cdot a \times 40.08 \times 1000 / V
$$

$M$-Molar concentration of EDTA standard solution, $\mathrm{mol} / \mathrm{L} ; a-$ Titrate the volume of EDTA standard solution, $\mathrm{mL} ; \mathrm{V}$-Volume of solution in beaker, $\mathrm{mL} ; 40.08$-Relative atomic weight of calcium.

Calculate the precipitation rate of calcium and lithium ions in the solution as shown in Formula (2).

$$
P_{e}=\left(C_{0}-C_{1}\right) / C_{0} \times 100 \%
$$


$P_{e}$-Ion precipitation rate, $\% ; C_{0}$-The mass concentration of calcium (or lithium) ions in the solution before treatment, $\mathrm{mg} / \mathrm{L} ; C_{1}$-The mass concentration of calcium (or lithium) ions in the solution after treatment, $\mathrm{mg} / \mathrm{L}$.

\subsection{Phosphate Precipitation Method for Lithium Recovery Experiment}

The lithium-containing filtrate obtained by removing calcium from oxalic acid under the optimal conditions is placed in a $100 \mathrm{~mL}$ beaker, and the beaker is placed in a constant temperature water bath, the molar ratio of $n\left(\mathrm{Na}_{3} \mathrm{PO}_{4}\right): n\left(\mathrm{Li}^{+}\right)(1.0: 1,1.1: 1,1.2: 1,1.3: 1,1.4: 1)$, weigh the corresponding $\mathrm{Na}_{3} \mathrm{PO}_{4}$ into the corresponding beaker, then adjust the $\mathrm{pH}$ value to 6.0 10 with dilute hydrochloric acid and $\mathrm{NaOH}$, and stirred at a constant speed of $200 \mathrm{r} \cdot \mathrm{min}^{-1}$ at $50 \sim 90{ }^{\circ} \mathrm{C}$, after reacting for $1.5 \mathrm{~h}$, the amount of filtered solid precipitation was measured. The schematic diagram from molten salt electrolysis to two-step lithium extraction is shown in Figure 1.

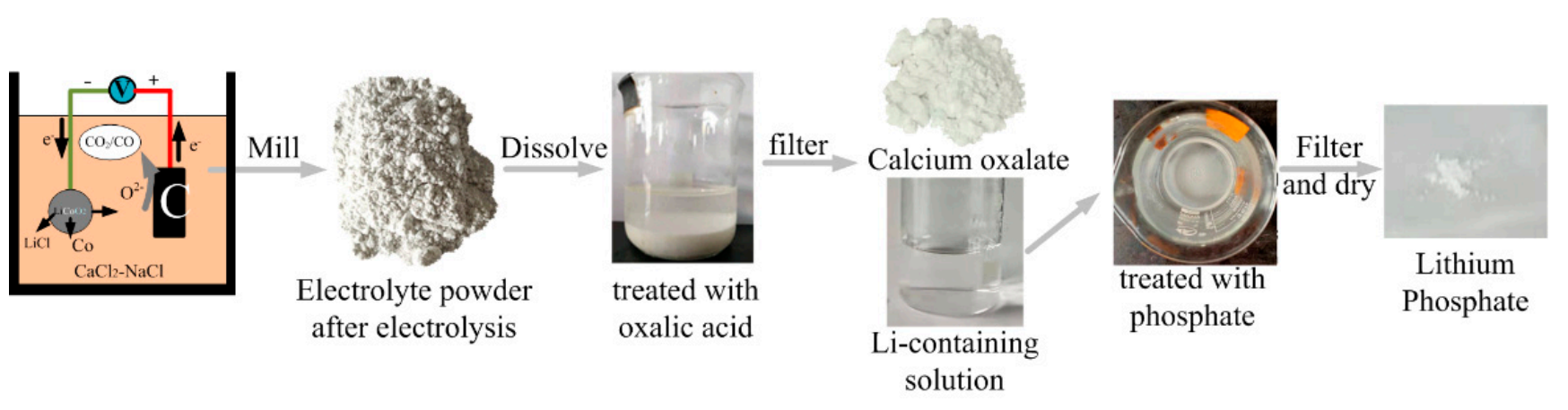

Figure 1. Schematic diagram of two-step lithium extraction.

\subsection{Characterization Equipment}

The content of residual calcium ions in the solution is determined by titration. Besides, the ion content in the solution before and after oxalic acid (or phosphate) treatment by an inductively coupled plasma atomic emission spectrometer (ICP-AES, Waltham, MA, USA). The phase of the product was analyzed by Noran7 X-ray diffractometer (XRD, Rigaku D/MAX2500PC, Tokyo, Japan). The morphology and element distribution of the particle surface of the experimental sample were analyzed by scanning electron microscope-energy spectroscopy (SEM-EDS, JEOL JEM-2800F, Tokyo, Japan).

\section{Results}

Figure 2 shows the XRD pattern of the electrolysis product and the molten salt after electrolysis. The cathode product of electrolysis at $1.3 \mathrm{~V}$ for $12 \mathrm{~h}$ is cobalt, which indicates that it is feasible to recover the metal $\mathrm{Co}$ in $\mathrm{LiCoO}_{2}$ by molten salt electrolysis. The presence of $\mathrm{LiCl}$ in the molten salt indicates that the lithium ions in $\mathrm{LiCoO}_{2}$ have entered the molten salt. Table 1 shows the ICP of a solution prepared by adding water to molten salt powder containing lithium ions. It shows that the solution contains a large amount of calcium ions and a small amount of lithium ions.

Table 1. Analyze the composition of the solution before oxalic acid treatment.

\begin{tabular}{ccc}
\hline Elements & Ca & Li \\
\hline Content $(\mathrm{mg} / \mathrm{L})$ & $21,040.6$ & 277 \\
\hline
\end{tabular}



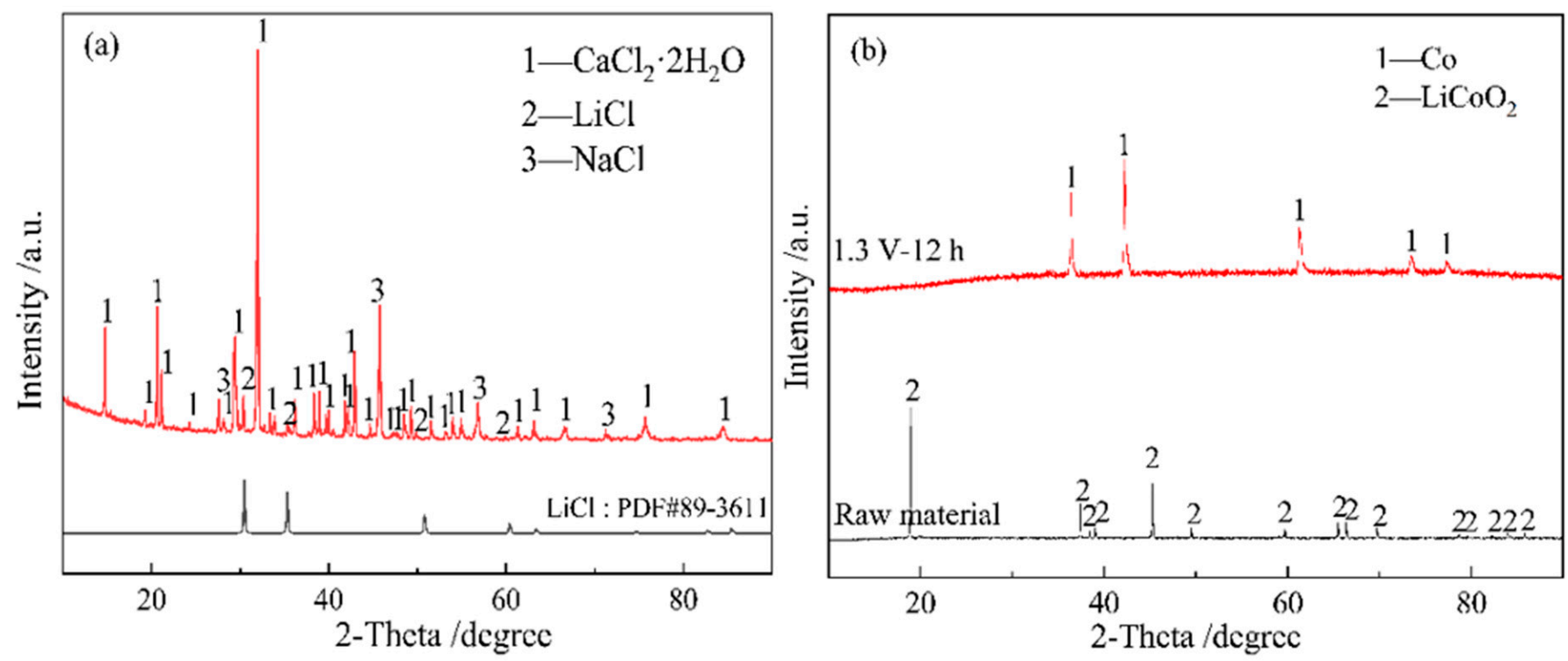

Figure 2. The XRD pattern of the electrolysis product of $\mathrm{LiCoO}_{2}$ in $\mathrm{CaCl}_{2}-\mathrm{NaCl}$ molten salt at $750{ }^{\circ} \mathrm{C}$ and the molten salt near the electrode: (a) molten salt near the cathode after electrolysis; (b) $\mathrm{LiCoO}_{2}$ electrolysis product.

\subsection{Study on Calcium Removal by Oxalic Acid Precipitation}

Calcium removal by oxalic acid precipitation means that calcium metal ions undergo a chemical reaction and precipitate under the action of an oxalic acid precipitant, and the reaction is Formula (3).

$$
\mathrm{H}_{2} \mathrm{C}_{2} \mathrm{O}_{4}+\mathrm{CaCl}_{2}=\mathrm{CaC}_{2} \mathrm{O}_{4} \downarrow+2 \mathrm{HCl}(\mathrm{g})
$$

The reaction and precipitation process can be realized under the combined action of factors such as $\mathrm{pH}$ value, temperature, time, and reactant concentration.

\subsubsection{The Effect of Oxalic Acid Addition on Calcium Precipitation Rate}

It can be seen from Figure 3 that when the initial $\mathrm{pH}$ value is 7.0, the reaction temperature is $50{ }^{\circ} \mathrm{C}$, and the stirring rate is $200 \mathrm{r} \cdot \mathrm{min}^{-1}$. As the ratio of $n\left(\mathrm{H}_{2} \mathrm{C}_{2} \mathrm{O}_{4}\right): n\left(\mathrm{Ca}^{2+}\right)$ increases, the removal rate of $\mathrm{Ca}^{2+}$ gradually increases, $n\left(\mathrm{H}_{2} \mathrm{C}_{2} \mathrm{O}_{4}\right): n\left(\mathrm{Ca}^{2+}\right)=1.2: 1$, the removal rate of $\mathrm{Ca}^{2+}$ is $93.23 \%$.

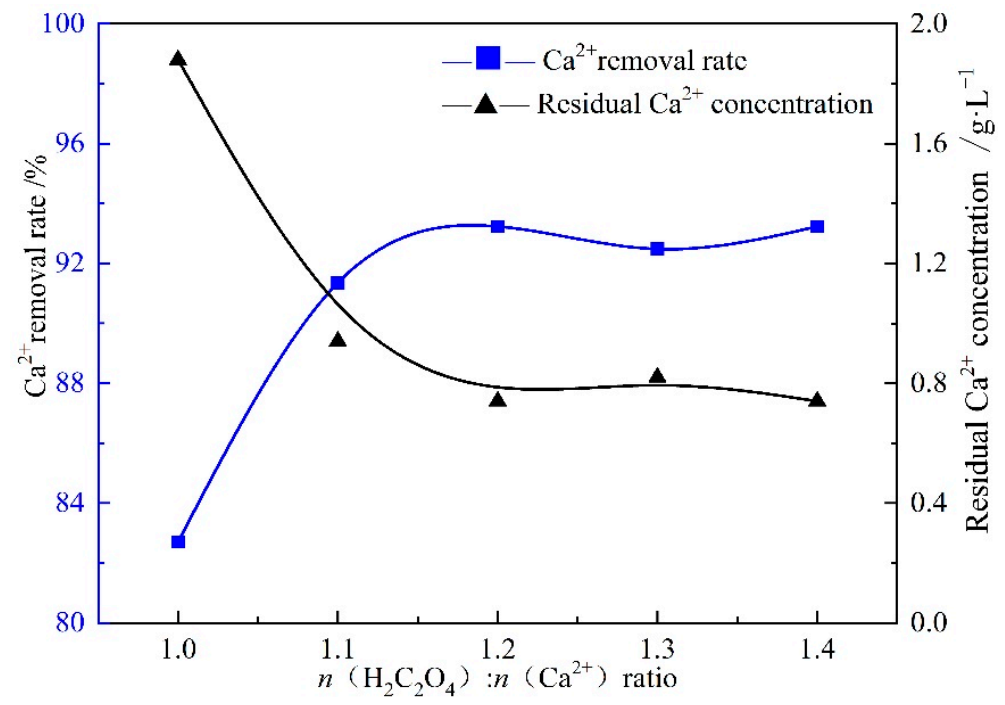

Figure 3. The influence of $n\left(\mathrm{H}_{2} \mathrm{C}_{2} \mathrm{O}_{4}\right): n\left(\mathrm{Ca}^{2+}\right)$ on the removal rate of $\mathrm{Ca}^{2+}$. 
During the precipitation reaction, the amount of precipitant added is a very important factor. Increasing the amount of precipitant added can significantly increase the precipitation rate of calcium oxalate. Analysis shows that under the same conditions of $\mathrm{Ca}^{2+}$ concentration, increasing the amount of oxalic acid will increase the amount of $\mathrm{C}_{2} \mathrm{O}_{4}{ }^{2-}$ produced by its ionization, thereby increasing the precipitation. Due to the same ion effect, the increase of the amount of $\mathrm{C}_{2} \mathrm{O}_{4}{ }^{2-}$ is also conducive to the precipitation-dissolution balance of calcium oxalate Move to the left to reduce its solubility. Therefore, as the molar ratio of reactants increases, the precipitation rate of calcium will increase.

According to the relationship between the total concentration of $\mathrm{Ca}^{2+},\{\mathrm{Ca}\}_{\mathrm{T}}$ and $\mathrm{pH}$ value at different $\left\{\mathrm{C}_{2} \mathrm{O}_{4}\right\}_{\mathrm{T}}$ concentrations [10], when $\mathrm{pH}<0.8$, as $\left\{\mathrm{C}_{2} \mathrm{O}_{4}\right\}_{\mathrm{T}}$ increases, the $\{\mathrm{Ca}\}_{\mathrm{T}}$ in the solution decreases. The $\mathrm{pH}$ of the solution in the middle of the experimental reaction and after the reaction was tested, and it was found that the $\mathrm{pH}$ was less than 0.5. The experimental results show that as the ratio of $n\left(\mathrm{H}_{2} \mathrm{C}_{2} \mathrm{O}_{4}\right): n\left(\mathrm{Ca}^{2+}\right)$ increases, the removal rate of calcium ions gradually increases.

\subsubsection{The Effect of Reaction Time on Calcium Precipitation Rate}

Figure 4 shows that the concentration of residual $\mathrm{Ca}^{2+}$ in the solution gradually decreases with the extension of the reaction time (The initial conditions are $\mathrm{PH}=7.0, T=50^{\circ} \mathrm{C}$, stirring rate $\left.=200 \mathrm{r} \cdot \mathrm{min}^{-1}, n\left(\mathrm{H}_{2} \mathrm{C}_{2} \mathrm{O}_{4}\right): n\left(\mathrm{Ca}^{2+}\right)=1.2: 1\right)$. After $1.5 \mathrm{~h}$, the concentration of $\mathrm{Ca}^{2+}$ in the solution is stable. With the increase of the reaction time, the precipitation reaction tends to be sufficient, and the precipitation of stable crystal forms gradually increases. But when the reaction time is long enough, the reaction reaches an equilibrium state, and if the time is extended, the concentration of $\mathrm{Ca}^{2+}$ in the solution will not change. The process of calcium oxalate precipitation is a process in which calcium oxalate precipitates crystal grains from the calcium-containing solution and grows up. When calcium oxalate particles are formed, some of them will stick together to form stable agglomerates, and some smaller particles will grow on the surface of larger particles, increasing the particle size.

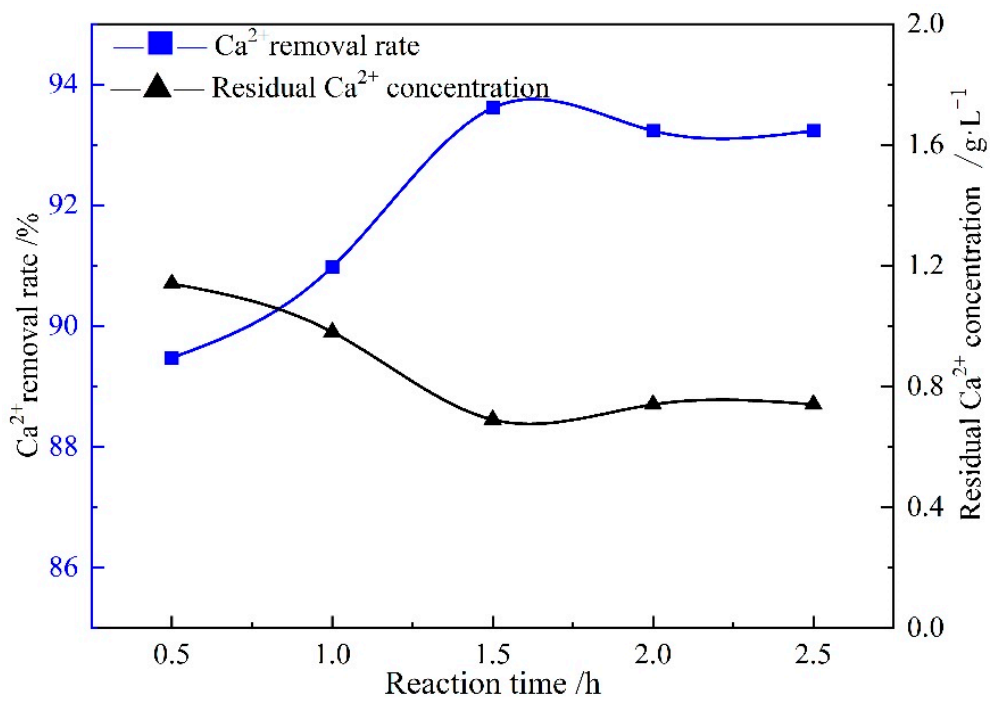

Figure 4. The relationship between reaction time and $\mathrm{Ca}^{2+}$ removal rate.

\subsubsection{The Effect of Reaction Temperature on Calcium Precipitation Rate}

When the $\mathrm{pH}$ is 7.0, $n\left(\mathrm{H}_{2} \mathrm{C}_{2} \mathrm{O}_{4}\right): n\left(\mathrm{Ca}^{2+}\right)=1.2: 1$, the reaction time is $1.5 \mathrm{~h}$, and the stirring rate is $200 \mathrm{r} \cdot \mathrm{min}^{-1}$, the relationship between the reaction temperature and the calcium precipitation rate is shown in Figure 5. The calcium precipitation rate first increases and then decreases with the increase of the reaction temperature, and reaches the highest when the reaction temperature is $70^{\circ} \mathrm{C}$. As the reaction temperature continues to increase, the precipitation rate will decrease. This is due to the fact that the increase in the reaction temperature increases the solubility of calcium oxalate, resulting in a decrease in the 
calcium precipitation rate. The formation of $\mathrm{HCl}$ in the process of removing calcium from oxalic acid makes the $\mathrm{pH}$ value of the solution gradually decrease as the reaction progresses. In acidic solutions, oxalic acid cannot be completely ionized, resulting in the formation of $\mathrm{H}_{2} \mathrm{C}_{2} \mathrm{O}_{4}, \mathrm{HC}_{2} \mathrm{O}_{4}{ }^{-}$and $\mathrm{C}_{2} \mathrm{O}_{4}{ }^{2-}$ [14], which in turn reduces the amount of $\mathrm{Ca}^{2+}$ precipitation and increases the remaining $\mathrm{Ca}^{2+}$ in the solution, which ultimately affects the decalcification effect. In addition, the increase in temperature is beneficial to the reaction, which speeds up the reaction rate and speeds up the rate of $\mathrm{HCl}$ generation. Since the $\mathrm{HCl}$ generated at high temperature is too late to volatilize, it quickly reacts with the generated $\mathrm{CaC}_{2} \mathrm{O}_{4}$ to regenerate $\mathrm{CaCl}_{2}$, resulting in a decrease in the efficiency of calcium removal.

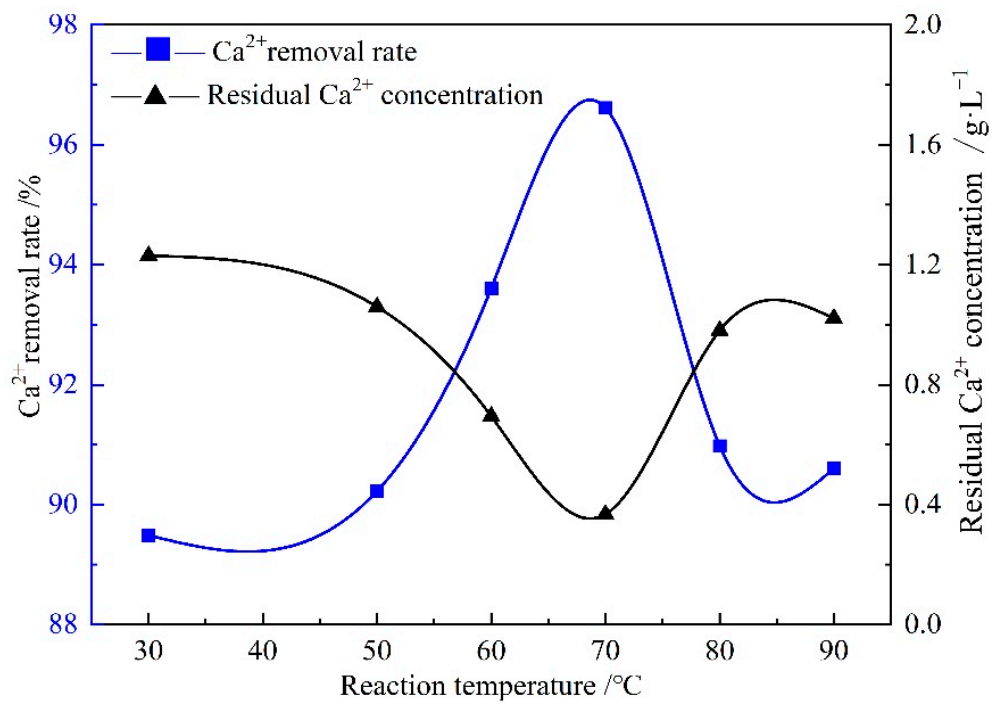

Figure 5. The relationship between reaction temperature and $\mathrm{Ca}^{2+}$ removal rate.

\subsubsection{The Effect of $\mathrm{NaOH}$ on Removing Calcium from Oxalic Acid}

By studying the influence of oxalic acid addition, reaction time, and reaction temperature on the calcium precipitation rate, a high calcium removal rate was not obtained and the removal effect was not ideal. Since the formation of the precipitate is affected by the $\mathrm{pH}$ of the solution during the reaction, the $\mathrm{HCl}$ generated during the decalcification reaction of oxalic acid reduces the $\mathrm{pH}$ of the solution during the reaction. To reduce the influence of $\mathrm{HCl}$ on calcium removal, the experiment was optimized by adding $\mathrm{NaOH}$ to adjust the $\mathrm{pH}$ value.

Figure 6 shows that when $n\left(\mathrm{H}_{2} \mathrm{C}_{2} \mathrm{O}_{4}\right): n\left(\mathrm{Ca}^{2+}\right)=1.2: 1$, the reaction is $1.5 \mathrm{~h}$, the reaction temperature is $70^{\circ} \mathrm{C}$, and the stirring rate is $200 \mathrm{r} \cdot \mathrm{min}^{-1}$, as $\mathrm{NaOH}$ and the theoretically generated $\mathrm{HCl}$ in the solution As the molar ratio increases, the removal rate of $\mathrm{Ca}^{2+}$ gradually increases to a certain level and then stabilizes. When the molar ratio of $\mathrm{NaOH}$ to the theoretically generated $\mathrm{HCl}$ in the solution is $0.7: 1$, the removal rate of $\mathrm{Ca}^{2+}$ is $99.72 \%$. With the increase of the amount of $\mathrm{NaOH}$ added, the $\mathrm{pH}$ of the solution increases. As the $\mathrm{pH}$ increases, the oxalic acid ionization is complete, and the concentration of $\mathrm{C}_{2} \mathrm{O}_{4}{ }^{2-}$ in the solution increases, resulting in a decrease in the concentration of remaining $\mathrm{Ca}^{2+}$ in the solution and an increase in the removal rate of calcium. From the distribution of $\mathrm{Ca}^{2+}$ in the $\mathrm{Ca}^{2+}-\mathrm{C}_{2} \mathrm{O}_{4}{ }^{2-}-\mathrm{Cl}-\mathrm{H}_{2} \mathrm{O}$ system [15], the main forms of calcium in the solution are free $\mathrm{Ca}^{2+}, \mathrm{Ca}_{m}\left(\mathrm{HC}_{2} \mathrm{O}_{4}\right)_{n}{ }^{2 m-n}$, and $\mathrm{Ca}_{m}\left(\mathrm{C}_{2} \mathrm{O}_{4}\right)_{n}{ }^{2 m-2 n}$. With the increase of $\mathrm{pH}$ value, the ratio of $\mathrm{Ca}_{m}\left(\mathrm{C}_{2} \mathrm{O}_{4}\right)_{n}{ }^{2 m-2}$ rises rapidly. When $\mathrm{pH}>3$, the ratio of $\mathrm{Ca}_{m}\left(\mathrm{C}_{2} \mathrm{O}_{4}\right) n^{2 m-2}$ gradually stabilizes. And when $\mathrm{pH}>2.7, \mathrm{Ca}^{2+}$ in the solution is mainly in the $\mathrm{Ca}_{m}\left(\mathrm{C}_{2} \mathrm{O}_{4}\right) n^{2 m-2 n}$ state. Therefore, when $\mathrm{NaOH}$ is not added, the solution is in a low $\mathrm{pH}$ environment during the reaction process, resulting in freer $\mathrm{Ca}^{2+}$, so the removal rate of calcium ions in a low $\mathrm{pH}$ environment is not high; After adding $\mathrm{NaOH}$, the $\mathrm{Ca}^{2+}$ in the solution is mainly in the $\mathrm{Ca}_{m}\left(\mathrm{C}_{2} \mathrm{O}_{4}\right)_{n}{ }^{2 m-2 n}$ state, and the calcium removal rate is improved. 


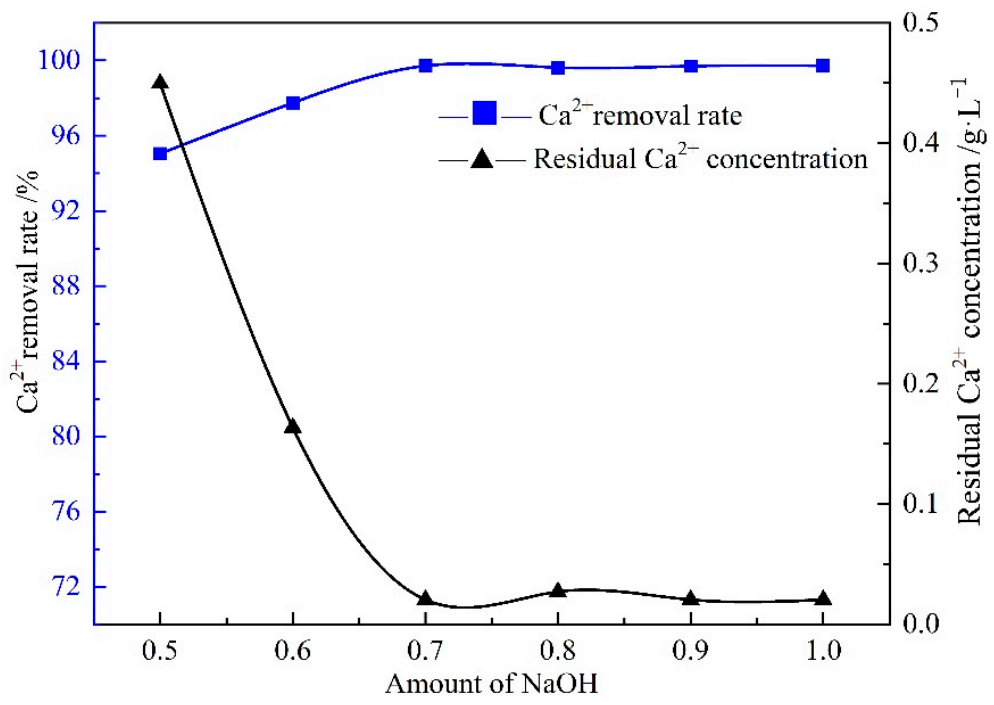

Figure 6. The relationship between the amount of $\mathrm{NaOH}$ added and the removal rate of $\mathrm{Ca}^{2+}$.

Table 2 shows the results of ICP in the remaining solution after removing the calcium oxalate precipitation (under conditions: $200 \mathrm{r} \cdot \mathrm{min}^{-1}, 70{ }^{\circ} \mathrm{C}, 1.5 \mathrm{~h}, n\left(\mathrm{H}_{2} \mathrm{C}_{2} \mathrm{O}_{4}\right): n\left(\mathrm{Ca}^{2+}\right)=1.2: 1$, $n(\mathrm{NaOH}): n$ (theoretically generated $\mathrm{HCl})=0.7: 1)$. It demonstrates that after treatment with oxalic acid and $\mathrm{NaOH}$, most of the calcium ions form calcium oxalate precipitates. The calcium ion content in the solution decreased from $21,040.6 \mathrm{mg} / \mathrm{L}$ to $58.91 \mathrm{mg} / \mathrm{L}$. As a small part of lithium ions are mixed into the calcium oxalate precipitate, the content of lithium ions is slightly reduced.

Table 2. Analyze the composition of the solution after oxalic acid and $\mathrm{NaOH}$ treatment.

\begin{tabular}{ccc}
\hline Elements & Ca & Li \\
\hline Content $(\mathrm{mg} / \mathrm{L})$ & 58.91 & 262.43 \\
\hline
\end{tabular}

Figure 7 shows that the precipitate is a relatively pure crystal of calcium oxalate, and its particles are observed to have an irregular geometric block structure with a size between 0.3 and $2 \mu \mathrm{m}$. Figure 7a shows that some smaller particles grow on the surface of larger particles, and agglomerate through the growth of these small particles to form stable agglomerates, thereby increasing the particle size. The analysis of the particles (point A) about $2 \mu \mathrm{m}$ shows that the atomic percentages of $\mathrm{Ca}, \mathrm{C}$, and $\mathrm{O}$ are $5.48 \%, 38.86 \%$, and $55.66 \%$, and the mass percentages are $14.55 \%, 41.17 \%$, and $44.28 \%$, respectively. In Figure $7 \mathrm{c}-\mathrm{e}$ are the results of particle surface scanning. The distribution of calcium and oxygen is more uniform, and the distribution of carbon is more concentrated in the upper part.

\subsection{Research on the Recovery of Lithium by Phosphate Precipitation Method}

The solution after precipitation by calcium oxalate contains lithium ion, and a precipitate is formed by adding $\mathrm{Na}_{3} \mathrm{PO}_{4}$ and $\mathrm{LiCl}$ to the solution, as shown in reaction (4). In this process, the main influencing factors of the reaction are the $\mathrm{pH}$ value of the solution, the reaction temperature and the amount of trisodium phosphate added. By studying the influence of several factors on the lithium precipitation rate, a better lithium precipitation condition is found.

$$
\mathrm{Na}_{3} \mathrm{PO}_{4}+3 \mathrm{LiCl}=\mathrm{Li}_{3} \mathrm{PO}_{4} \downarrow+3 \mathrm{NaCl}
$$



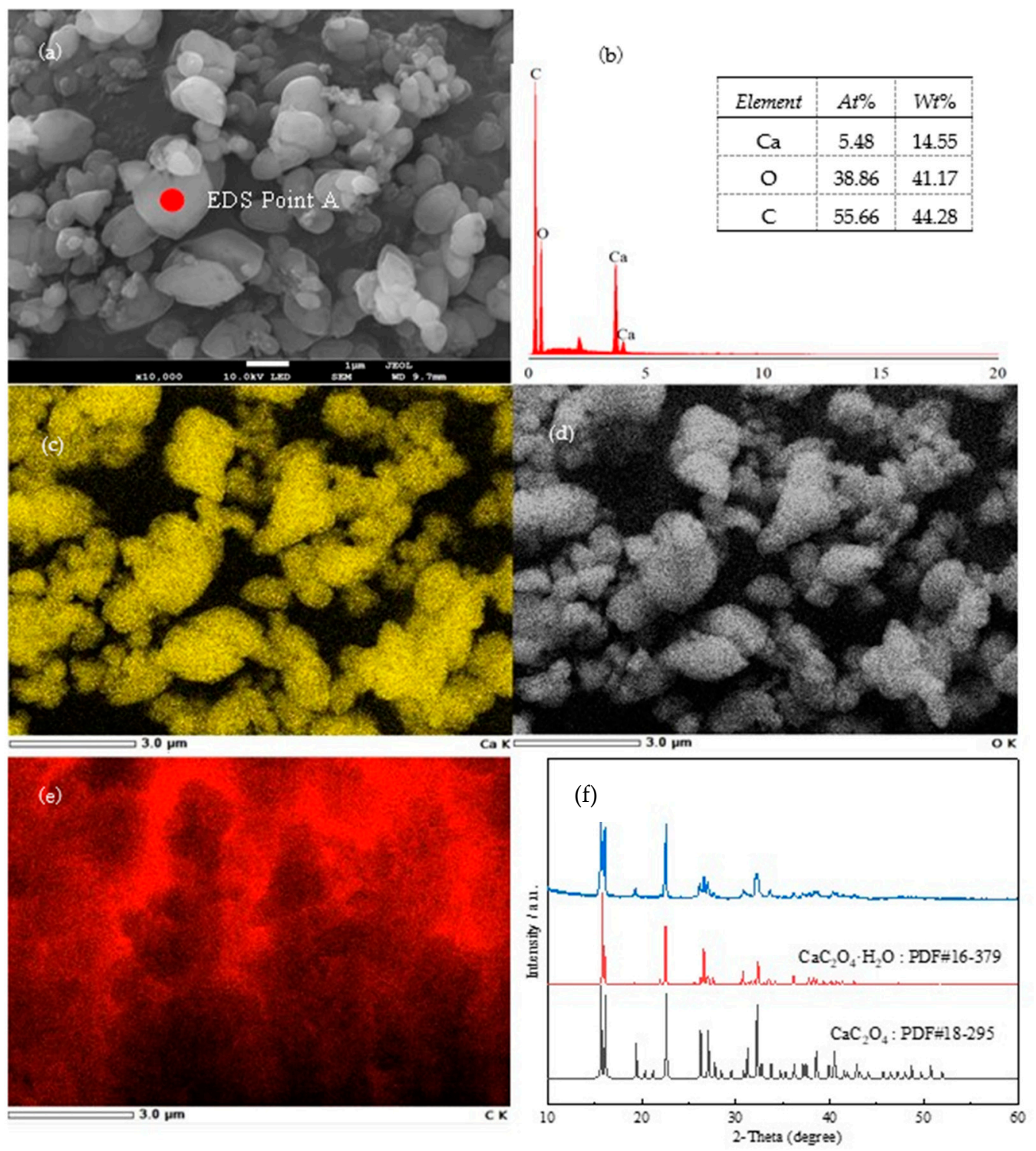

Figure 7. Characterization of the product calcium oxalate: (a) SEM of calcium oxalate, (b) calcium oxalate A point EDS analysis, (c) calcium element distribution in calcium oxalate, (d) oxygen element distribution in calcium oxalate, (e) carbon element distribution in calcium oxalate, and (f) XRD of the final calcium oxalate obtained under corresponding conditions (The conditions are: $200 \mathrm{r} \cdot \mathrm{min}^{-1}$, $70{ }^{\circ} \mathrm{C}, 1.5 \mathrm{~h}, n\left(\mathrm{H}_{2} \mathrm{C}_{2} \mathrm{O}_{4}\right): n\left(\mathrm{Ca}^{2+}\right)=1.2: 1, n(\mathrm{NaOH}): n($ theoretically generated $\left.\mathrm{HCl})=0.7: 1\right)$.

\subsubsection{The Influence of $\mathrm{pH}$ on Lithium Precipitation Rate}

Weigh the corresponding $\mathrm{Na}_{3} \mathrm{PO}_{4}$ when the molar ratio of the actual amount of $\mathrm{Na}_{3} \mathrm{PO}_{4}$ to the theoretical amount is $1: 1$, and then add it to the beaker containing the lithiumcontaining solution after decalcification. Carry out the lithium precipitation experiment under the condition of stirring rate of $200 \mathrm{r} \cdot \mathrm{min}^{-1}$ at room temperature. Figure 8 shows that the lithium precipitation rate increases with the increase of $\mathrm{pH}$. This is due to the fact that under acidic conditions, $\mathrm{H}^{+}$and $\mathrm{PO}_{4}{ }^{3-}$ produce $\mathrm{HPO}_{4}{ }^{2-}$ and $\mathrm{H}_{2} \mathrm{PO}_{4}{ }^{-}$, and then $\mathrm{Li}^{+}$ and $\mathrm{HPO}_{4}{ }^{2-}$ and $\mathrm{H}_{2} \mathrm{PO}_{4}{ }^{-}$produce $\mathrm{Li}_{2} \mathrm{HPO}_{4}$ and $\mathrm{LiH}_{2} \mathrm{PO}_{4}$, and $\mathrm{Li}_{2} \mathrm{HPO}_{4}$ and $\mathrm{LiH}_{2} \mathrm{PO}_{4}$ are more soluble in water and part of $\mathrm{Li}^{+}$dissolves in solution. In this way, it affects the recovery rate of lithium. When the reaction $\mathrm{pH}>8$, the reaction reaches equilibrium and the lithium precipitation rate in the solution tends to be stable. 


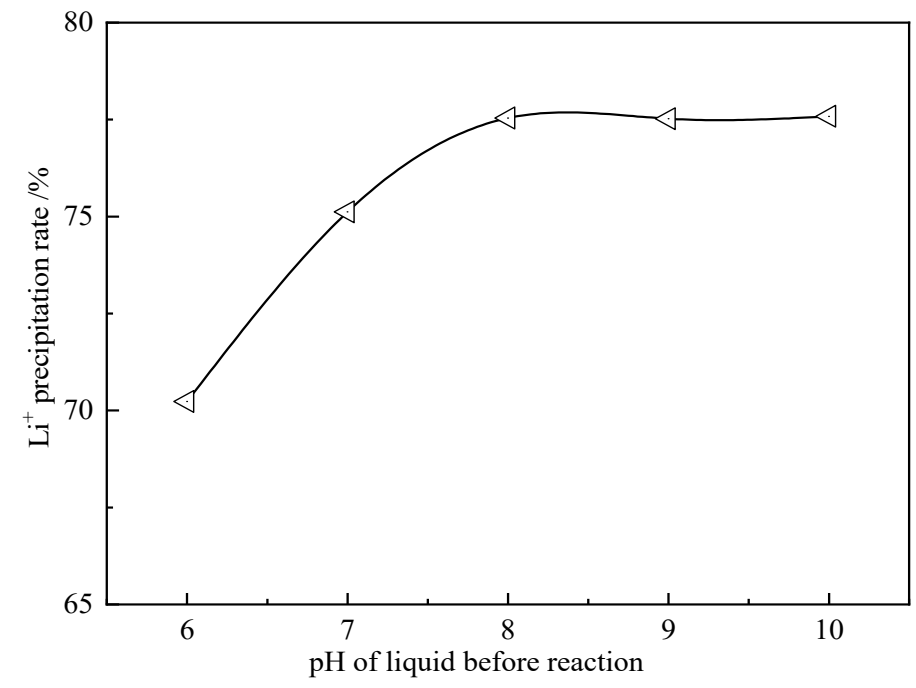

Figure 8. The relationship between $\mathrm{pH}$ value and $\mathrm{Li}^{+}$recovery.

3.2.2. The Influence of Reaction Temperature on Lithium Precipitation Rate

Adjusting the $\mathrm{pH}$ value of the solution to 8 can increase the precipitation rate of $\mathrm{Li}$, and inhibit the hydrolysis of trisodium phosphate. When the molar ratio of the actual amount of $\mathrm{Na}_{3} \mathrm{PO}_{4}$ to the theoretical amount is 1:1, the effect of the reaction temperature on the lithium precipitation rate is shown in Figure 9. When the reaction temperature is $70{ }^{\circ} \mathrm{C}$, the precipitation rate of $\mathrm{Li}^{+}$has reached $86.57 \%$. This result shows that the higher the temperature, the more favorable the $\mathrm{Na}_{3} \mathrm{PO}_{4}$ precipitation of lithium. Table 3 shows that the Gibbs free energy of the reaction does not change significantly as the temperature increases, so the increase in the amount of lithium-ion precipitation is attributed to molecules obtain higher energy as the temperature increases, and the frequency of intermolecular collisions increases. The collisions cause more activated molecules to participate in the reaction and accelerate the reaction rate, promoting the progress of the reaction. As the reaction temperature continues to increase, the amount of lithium precipitation tends to balance.

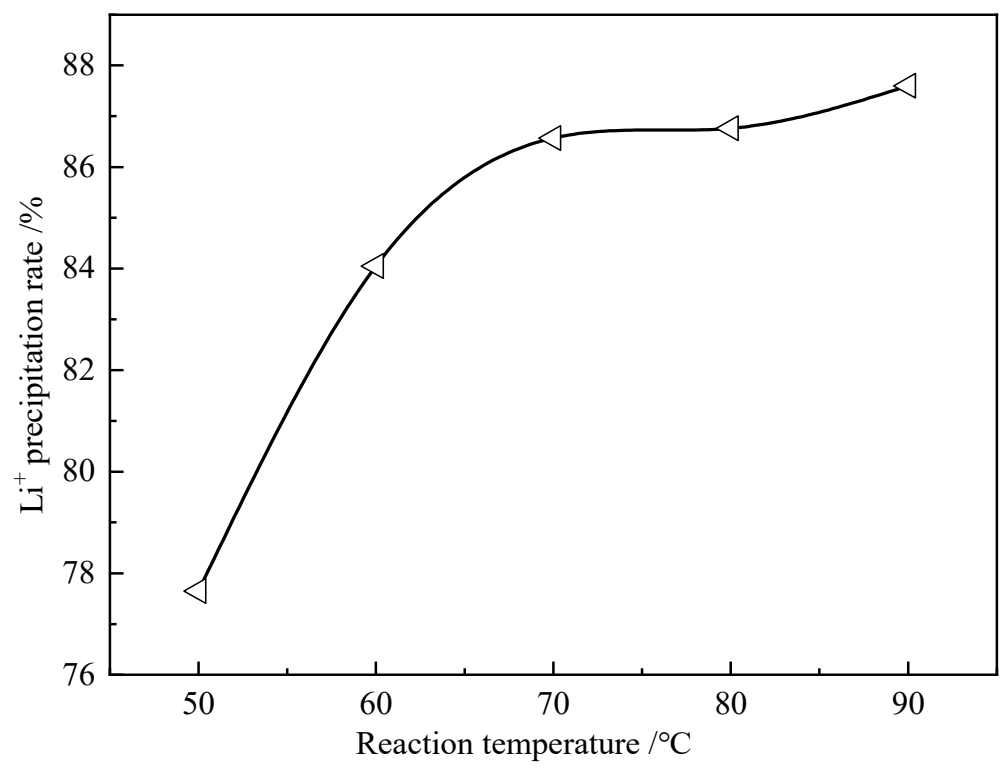

Figure 9. The relationship between reaction temperature and $\mathrm{Li}^{+}$recovery. 
Table 3. The Gibbs Free Energy Change of the Reaction of $\mathrm{Na}_{3} \mathrm{PO}_{4}$ and $\mathrm{LiCl}$ at $50-100{ }^{\circ} \mathrm{C}$ (by $\mathrm{HSC}$ Chemistry 6.0 software (Outokumpu, France)).

\begin{tabular}{cc}
\hline$T /{ }^{\circ} \mathbf{C}$ & $\Delta G^{\boldsymbol{\Theta}} / \mathbf{k J}$ \\
\hline 50 & -177.084 \\
60 & -176.775 \\
70 & -176.465 \\
80 & -176.153 \\
90 & -175.839 \\
\hline
\end{tabular}

\subsubsection{The Effect of Trisodium Phosphate Addition on Lithium Precipitation Rate}

According to formula (4), the increase of the $\mathrm{PO}_{4}{ }^{3-}$ concentration in the solution facilitates the reaction to increase the production of $\mathrm{Li}_{3} \mathrm{PO}_{4}$. Figure 10 shows that the precipitation rate of lithium ions increases significantly with the increase in the molar ratio of the actual dosage of $\mathrm{Na}_{3} \mathrm{PO}_{4}$ to the theoretical dosage under the conditions of $\mathrm{pH}=8.0,70{ }^{\circ} \mathrm{C}$ and stirring rate $200 \mathrm{r} \cdot \mathrm{min}^{-1}$. When the actual dosage of $\mathrm{Na}_{3} \mathrm{PO}_{4}$ to the theoretical dosage ratio exceeds 1.2 , the lithium-ion precipitation rate is basically unchanged. Under the same lithium-ion concentration condition, increasing the amount of trisodium phosphate will result in the increase of $\mathrm{PO}_{4}{ }^{3-}$ produced by its ionization, and the more precipitation will be produced.

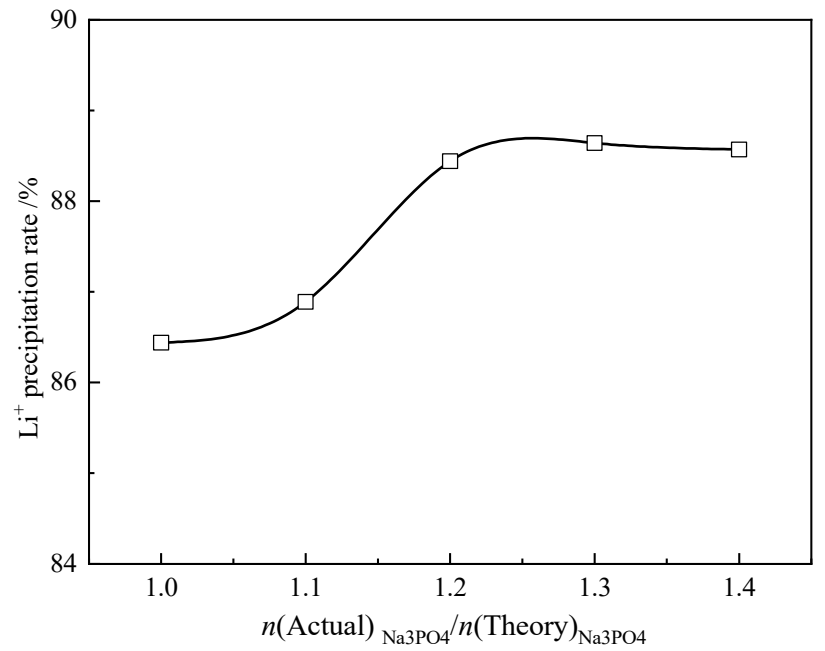

Figure 10. The influence of the molar ratio of the actual dosage and the theoretical dosage of trisodium phosphate on the recovery rate of $\mathrm{Li}^{+}$.

Table 4 shows the results of ICP in the remaining solution after removing the precipitate (under conditions: $200 \mathrm{r} \cdot \mathrm{min}^{-1}, 70{ }^{\circ} \mathrm{C}, 1.5 \mathrm{~h}, \mathrm{PH}=8, n$ (actual dosage of $\mathrm{Na}_{3} \mathrm{PO}_{4}$ ): $n$ (theoretical dosage of $\left.\left.\mathrm{Na}_{3} \mathrm{PO}_{4}\right)=1.2: 1\right)$. It can be seen from Table 4 that the content of lithium ions in the solution is greatly reduced to $30.337 \mathrm{mg} / \mathrm{L}$. A small amount of lithium ions remain in the solution, and the remaining lithium ions and phosphate form a lithium phosphate precipitate.

Table 4. Content of solution composition after precipitation of lithium phosphate.

\begin{tabular}{ccc}
\hline Elements & Ca & Li \\
\hline Content $(\mathrm{mg} / \mathrm{L})$ & 58.91 & 30.337 \\
\hline
\end{tabular}

Figure 11 is the characterization of lithium phosphate precipitation. It can be seen that the precipitate is a relatively pure lithium phosphate crystal. The obtained lithium phosphate is relatively regular spherical particles, the diameter of the large particles is about $4 \mu \mathrm{m}$, and the diameter of the small particles is about $0.7 \mu \mathrm{m}$. Figure 11a shows 
that some smaller lithium phosphate particles grow on the surface of the larger lithium phosphate particles. The growth and agglomeration of small particles increase the size of lithium phosphate particles. The atomic percentages of $\mathrm{P}$ and $\mathrm{O}$ in the large particles (point A) are $20.79 \%$ and $79.21 \%$, respectively, and the mass percentages are $33.69 \%$ and $66.31 \%$, respectively. Figure $11 \mathrm{c}, \mathrm{d}$ show the distribution of elements. The results show that the distribution of phosphorus and oxygen is relatively uniform. Since the corresponding energy in the X-ray spectrum of $\mathrm{Li}$ is too small, it cannot be detected by EDS.

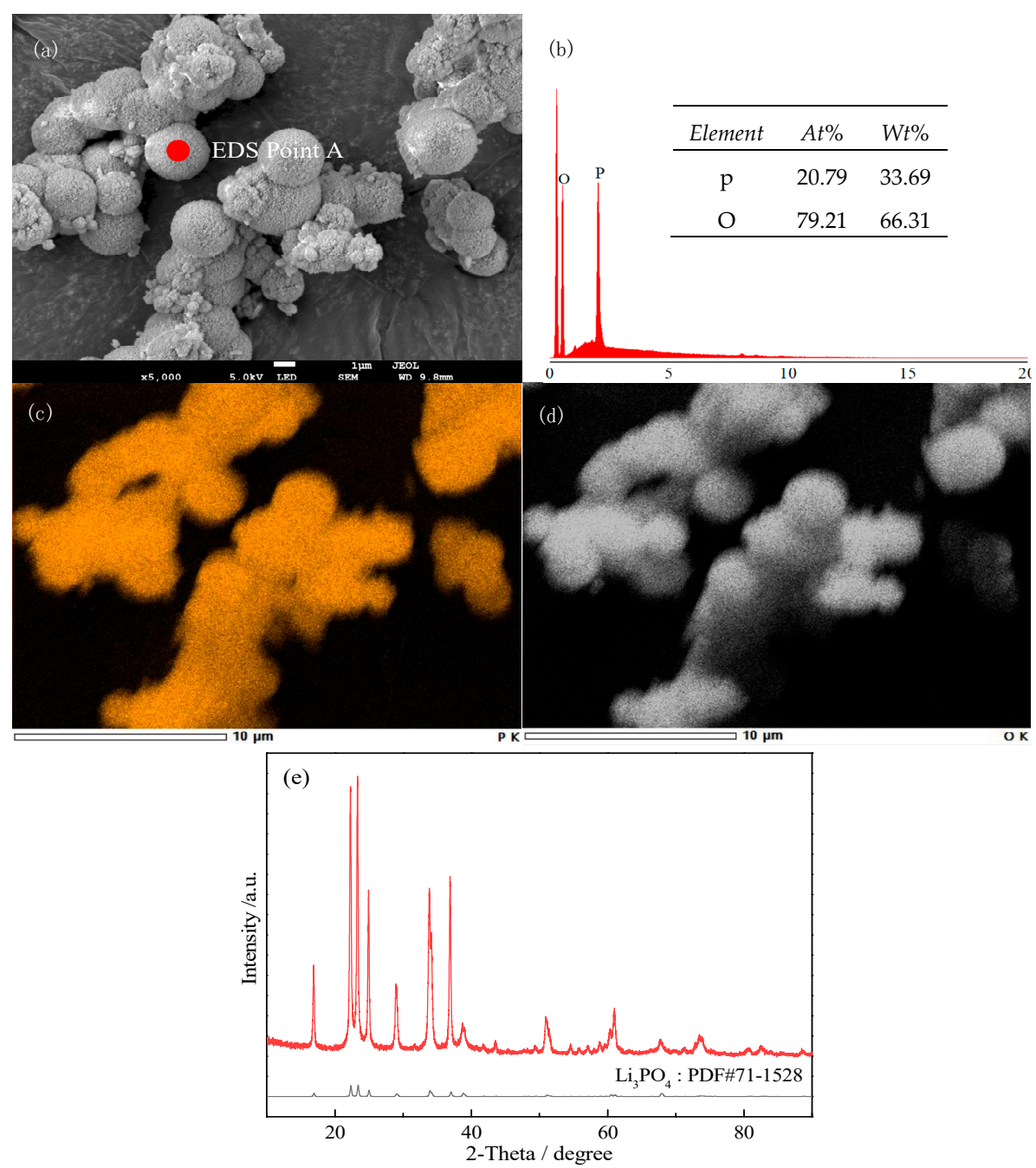

Figure 11. Characterization of phosphate precipitated lithium products: (a) electron micrograph of lithium phosphate; (b) EDS analysis of lithium phosphate A point; (c) phosphorus element distribution in lithium phosphate; (d) oxygen element distribution in lithium phosphate; and (e) XRD of the final lithium phosphate obtained under corresponding conditions (The conditions are: $200 \mathrm{r} \cdot \mathrm{min}^{-1}, 70^{\circ} \mathrm{C}$, $1.5 \mathrm{~h}, \mathrm{PH}=8, n\left(\right.$ actual dosage of $\left.\mathrm{Na}_{3} \mathrm{PO}_{4}\right): n\left(\right.$ theoretical dosage of $\left.\mathrm{Na}_{3} \mathrm{PO}_{4}\right)=1.2: 1$ ).

\section{Conclusions}

Two-step precipitation and extraction of lithium from the molten salt after electrolysis of $\mathrm{LiCoO}_{2}$ were carried out, and the influence of factors such as $\mathrm{pH}$, temperature, time, and reactant concentration on the precipitation reaction in the process of removing calcium from oxalic acid was obtained. And in the process of phosphate lithium precipitation, the $\mathrm{pH}$ value, temperature, and the addition amount of trisodium phosphate affect the lithium precipitation rate. At the same time, the two-step precipitation product was characterized, and the following conclusions were drawn: 
(1) When oxalic acid precipitates and removes calcium ions in the solution, the stirring rate is $200 \mathrm{r} \cdot \mathrm{min}^{-1}$, the $\mathrm{pH}$ is 7.0 , the reaction temperature is $50^{\circ} \mathrm{C}$, and the concentration ratio of calcium oxalate to calcium ions in the solution is changed $n\left(\mathrm{H}_{2} \mathrm{C}_{2} \mathrm{O}_{4}\right): n\left(\mathrm{Ca}^{2+}\right)$; when the ratio increases from 1.0 to 1.1, the removal rate of calcium increases, and when it is greater than 1.1, the precipitation rate tends to balance; when the $\mathrm{pH}$ is 7.0 , the reaction temperature is $50{ }^{\circ} \mathrm{C}$, and $n\left(\mathrm{H}_{2} \mathrm{C}_{2} \mathrm{O}_{4}\right): n\left(\mathrm{Ca}^{2+}\right)=1.2: 1$, the calcium oxalate precipitation reaction increases significantly with time when it is less than $1.5 \mathrm{~h}$, and tends to balance after more than $1.5 \mathrm{~h}$; When the $\mathrm{pH}$ is 7.0, $n\left(\mathrm{H}_{2} \mathrm{C}_{2} \mathrm{O}_{4}\right): n\left(\mathrm{Ca}^{2+}\right)=1.2: 1$, and the reaction time is $1.5 \mathrm{~h}$, as the reaction temperature increases, the precipitation rate of calcium oxalate increases and then decreases, reaching a peak at $70{ }^{\circ} \mathrm{C}$; by adjusting the $\mathrm{pH}$ value of the solution, under the conditions of $n\left(\mathrm{H}_{2} \mathrm{C}_{2} \mathrm{O}_{4}\right): n\left(\mathrm{Ca}^{2+}\right)=1.2: 1$, the reaction time is $1.5 \mathrm{~h}$, the reaction temperature is 70 , and the molar ratio of $\mathrm{NaOH}$ to theoretically generated $\mathrm{HCl}$ is $0.7: 1$, the calcium removal rate of oxalic acid reaches $99.72 \%$. Calcium oxalate particles are irregular geometric block structure, the size is between $0.3 \sim 2 \mu \mathrm{m}$.

(2) During the phosphate precipitation process, under the condition of a stirring rate of $200 \mathrm{r} \cdot \mathrm{min}^{-1}$, the precipitation of lithium phosphate increases with the increase of the $\mathrm{pH}$ value of the solution. When the reaction $\mathrm{pH}>8$, the precipitation rate tends to balance; When the $\mathrm{pH}$ value is 8 and the molar ratio of the actual amount of trisodium phosphate to the theoretical amount is 1.2:1, the precipitation rate of lithium phosphate is proportional to the temperature, and tends to balance after reaching $70{ }^{\circ} \mathrm{C}$; The reaction reached equilibrium. Under the conditions that the reaction time was $1.5 \mathrm{~h}$, the solution $\mathrm{pH}=8$, the reaction temperature was $70^{\circ} \mathrm{C}$, and the molar ratio of the actual amount of trisodium phosphate to the theoretical amount was 1.2:1, the precipitation rate of lithium reached $88.44 \%$. Lithium phosphate precipitates as relatively pure lithium phosphate crystals, which are relatively regular spherical particles.

Author Contributions: Conceptualization, H.L. (Hui Li); methodology, H.L. (Haotian Li); validation, H.Y.; investigation, J.L.; resources, Z.C. All authors have read and agreed to the published version of the manuscript.

Funding: This research was funded by the National Natural Science Foundation of China, grant number 51774143 .

Institutional Review Board Statement: Not applicable.

Informed Consent Statement: Not applicable.

Data Availability Statement: Not applicable.

Acknowledgments: This study is financially supported by the National Natural Science. Foundation of China.

Conflicts of Interest: The authors declare no conflict of interest.

\section{References}

1. Gao, Y.; Li, Y.; Li, J.; Xie, H.; Chen, Y. Direct recovery of $\mathrm{LiCoO}_{2}$ from the recycled lithium-ion batteries via structure restoration. J. Alloys Compd. 2020, 845, 156234. [CrossRef]

2. Li, L.; Dunn, J.B.; Zhang, X.X.; Gaines, L.; Chen, R.J.; Wu, F.; Amine, K. Recovery of metals from spent lithium-ion batteries with organic acids as leaching reagents and environmental assessment. J. Power Sources 2013, 233, 180-189. [CrossRef]

3. Li, L.; Qu, W.; Zhang, X.; Lu, J.; Chen, R.; Wu, F.; Amine, K. Succinic acid-based leaching system: A sustainable process for recovery of valuable metals from spent li-ion batteries. J. Power Sources 2015, 282, 544-551. [CrossRef]

4. Chen, M.; Zheng, Z.; Wang, Q.; Zhang, Y.; Ma, X.; Shen, C.; Xu, D.; Liu, J.; Liu, Y.; Gionet, P. Closed loop recycling of electric vehicle batteries to enable ultra-high quality cathode powder. Sci. Rep. 2019, 9, 1654. [CrossRef] [PubMed]

5. Liu, K.; Zhang, F.-S. Innovative leaching of cobalt and lithium from spent lithium-ion batteries and simultaneous dechlorination of polyvinyl chloride in subcritical water. J. Hazard. Mater. 2016, 316, 19-25. [CrossRef] [PubMed]

6. Yu, C.-J.; Mo, X.-Y.; Kang, C.-R.; Ni, C.; Ding, Y. Progress in synthesis and modification of $\mathrm{LiFePO}_{4}$ cathode material for lithium ion rechargeable batteries. J. Mater. Sci. Eng. 2011, 3, 468-470. 
7. Wang, Y.; Yang, R.; Miao, J.L.; Zhao, R.R. One-step recycling of trinary cathode materials in lithium ion batteries and the impact on their performance. J. South Chin. Norm. Univ. (Nat. Sci. Ed.) 2021, 53, 36-41.

8. Natarajan, S.; Anantharaj, S.; Tayade, R.J.; Bajaj, H.C.; Kundu, S. Recovered spinel $\mathrm{MnCo}_{2} \mathrm{O}_{4}$ from spent lithium-ion batteries for enhanced electrocatalytic oxygen evolution in alkaline medium. Dalton Trans. 2017, 46, 14382-14392. [CrossRef] [PubMed]

9. Etacheri, V.; Marom, R.; Elazari, R.; Salitra, G.; Aurbach, D. Challenges in the development of advanced li-ion batteries: A review. Energ. Environ. Sci. 2011, 4, 3243-3262. [CrossRef]

10. Siqi, Z.; Guangming, L.; Wenzhi, H.; Juwen, H.; Haochen, Z. Recovery methods and regulation status of waste lithium-ion batteries in china: A mini review. Waste Manag. Res. 2019, 37, 1142-1152. [CrossRef] [PubMed]

11. Zhang, W.; Xu, C.; He, W.; Li, G.; Huang, J. A review on management of spent lithium ion batteries and strategy for resource recycling of all components from them. Waste Manag. Res. 2018, 36, 99-112. [CrossRef] [PubMed]

12. Deng, C.; Wang, X.J.; Yu, Q. Edta disodium titration method to determine the titration end point of calcium ion content. For. Eng. 2000, 02, 18-53.

13. Wang, Y.R. The interruption and its elimination of iron ion in edta titration of calcium and magnesium ion. J. Shanghai Inst. Technol. (Nat. Sci.) 2003, 04, 231-233.

14. Wang, W.; Chen, W.; Liu, H. Hydrometallurgical preparation of lithium carbonate from lithium-rich electrolyte. Hydrometallurgy 2019, 185, 88-92. [CrossRef]

15. Tian, Q.H. Study on Preparation of Cobalt Oxide by Precipitation Thermolysis Process of Oxalic Acid without Ammonia and Recovery Utilization of the Mother Liquor. Ph.D. Thesis, Central South University, Changsha, China, 2009. 